\title{
Sympathetic Innervation of Cold-Activated Brown and White Fat in Lean Young Adults
}

\author{
Otto Muzik ${ }^{1,2}$, Tom J. Mangner ${ }^{1}$, William R. Leonard ${ }^{3}$, Ajay Kumar ${ }^{1}$, and James G. Granneman ${ }^{4,5}$ \\ ${ }^{1}$ Department of Pediatrics, Wayne State University School of Medicine, Detroit, Michigan; ${ }^{2}$ Department of Radiology, Wayne State \\ University School of Medicine, Detroit, Michigan; ${ }^{3}$ Department of Anthropology, Northwestern University, Evanston, Illinois; ${ }^{4}$ Center \\ for Molecular Medicine and Genetics, Wayne State University School of Medicine, Detroit, Michigan; and ${ }^{5}$ Center for Integrative \\ Metabolic and Endocrine Research and Family Medicine
}

Recent work in rodents has demonstrated that basal activity of the local sympathetic nervous system is critical for maintaining brown adipocyte phenotypes in classic brown adipose tissue (BAT) and white adipose tissue (WAT). Accordingly, we sought to assess the relationship between sympathetic innervation and cold-induced activation of BAT and WAT in lean young adults. Methods: Twenty adult lean normal subjects (10 women and 10 men; mean age $\pm \mathrm{SD}, 23.3 \pm 3.8 \mathrm{y}$; body mass index, $\left.23.7 \pm 2.5 \mathrm{~kg} / \mathrm{m}^{2}\right)$ underwent ${ }^{11} \mathrm{C}$-meta-hydroxyephedrin $\left({ }^{11} \mathrm{C}-\mathrm{HED}\right)$ and ${ }^{15} \mathrm{O}$-water PET imaging at rest and after exposure to mild cold $\left(16^{\circ} \mathrm{C}\right)$ temperature. In addition, ${ }^{18} \mathrm{~F}-\mathrm{FDG}$ images were obtained during the cold stress condition to assess cold-activated BAT mass. Subjects were divided into 2 groups (high BAT and low BAT) based on the presence of ${ }^{18} \mathrm{~F}-\mathrm{FDG}$ tracer uptake. Blood flow and ${ }^{11} \mathrm{C}-\mathrm{HED}$ retention index $(\mathrm{Rl}$, an indirect measure of sympathetic innervation) were calculated from dynamic PET scans at the location of BAT and WAT. Whole-body daily energy expenditure (DEE) during rest and cold stress was measured by indirect calorimetry. Tissue level oxygen consumption $\left(\mathrm{MRO}_{2}\right)$ was determined and used to calculate the contribution of cold-activated BAT and WAT to daily DEE. Results: ${ }^{18} \mathrm{~F}-\mathrm{FDG}$ uptake identified subjects with high and low levels of cold-activated BAT mass (high BAT, $96 \pm 37 \mathrm{~g}$; lowBAT, $16 \pm 4$ g). ${ }^{11} \mathrm{C}$-HED RI under thermoneutral conditions significantly predicted ${ }^{18} \mathrm{~F}-\mathrm{FDG}$ uptake during cold stress $\left(R^{2}=0.68, P<0.01\right)$. In contrast to the significant increase of ${ }^{11} \mathrm{C}-\mathrm{HED} \mathrm{RI}$ during cold in BAT ( $2.42 \pm 0.85$ vs. $3.43 \pm 0.93, P=0.02$ ), cold exposure decreased the ${ }^{11} \mathrm{C}$-HED RI in WAT (0.44 \pm 0.22 vs. $\left.0.41 \pm 0.18\right)$ as a consequence of decreased perfusion (1.22 \pm 0.20 vs. $1.12 \pm 0.16 \mathrm{~mL} / 100 \mathrm{~g} / \mathrm{min}$ ). The contribution of WAT to whole-body DEE was approximately $150 \mathrm{kcal} / \mathrm{d}$ at rest $(149 \pm 52 \mathrm{kcal} / \mathrm{d})$, which decreased to approximately $100 \mathrm{kcal} / \mathrm{d}$ during cold $(102 \pm 47 \mathrm{kcal} / \mathrm{d})$. Conclusion: The level of sympathetic innervation, as determined by ${ }^{11} \mathrm{C}$-HED RI, can predict levels of functional BAT. Overall, blood flow is the best independent predictor of ${ }^{11} \mathrm{C}-\mathrm{HED} \mathrm{RI}$ and ${ }^{18} \mathrm{~F}-\mathrm{FDG}$ uptake across thermoneutral and cold conditions. In contrast to BAT, cold stress reduces blood flow and ${ }^{18} \mathrm{~F}-\mathrm{FDG}$ uptake in subcutaneous WAT, indicating that the physiologic response is to reduce heat loss rather than to generate heat.

Key Words: brown fat; subcutaneous fat; sympathetic innervation; HED PET imaging

J Nucl Med 2017; 58:799-806

DOI: 10.2967/jnumed.116.180992

Received Jul. 12, 2016; revision accepted Sep. 28, 2016

For correspondence or reprints contact: Otto Muzik, PET Center, Children's Hospital of Michigan, 3901 Beaubien Blvd., Detroit, MI 48201.

E-mail: otto@pet.wayne.edu

Published online Oct. 27, 2016.

COPYRIGHT (C 2017 by the Society of Nuclear Medicine and Molecular Imaging.
$\mathbf{T}$ he main function of brown adipocytes in mammals is the generation of heat in response to cold stress. In addition to comprising the parenchyma of classic interscapular brown adipose tissue (BAT), brown adipocytes (BA) can be found dispersed in various white adipose tissue (WAT) depots $(1,2)$. Cold stress is a powerful physiologic stimulus for activating parenchymal BA cells in BAT as well as recruiting their appearance in typical WAT depots $(3,4)$. Recent work has clearly established the presence of BA cells in the supraclavicular region of humans $(5,6)$. Whether these cells more closely resemble typical BA cells found in classic BAT or BA cells that appear in WAT is controversial $(2,7)$. Nonetheless, the functional activation of BA cells can be clearly induced by mild cold stress in humans, although the presence and abundance of BAT varies greatly for reasons that are presently unclear.

The sympathetic nervous system is the major regulator of coldinduced BAT activity and mass in rodents $(8,9)$. Perhaps not surprisingly, the recruitment of BA cells in WAT depots by cold stress or direct beta3 adrenergic activation is correlated with the density of sympathetic innervation of individual fat pads (being greatest in subcutaneous and least in visceral fat) $(1,8)$. Importantly, chronic sympathetic denervation of WAT pads impairs the ability of direct beta3 receptor agonists to induce the BA phenotypes in WAT, indicating that the ability of phenotypic flexibility of subcutaneous WAT depends on ongoing sympathetic activity (10). On the basis of these data, we hypothesized that variations in the presence of supraclavicular BAT in humans will be directly related to the level of sympathetic innervation.

The norepinephrine analog ${ }^{11} \mathrm{C}$-meta-hydroxyephedrine $\left({ }^{11} \mathrm{C}\right.$-HED) has been widely used in PET imaging to map the regional sympathetic innervation of the heart $(11,12)$ and other tissues $(13)$. As a structural analog of the neurotransmitter norepinephrine, ${ }^{11} \mathrm{C}-\mathrm{HED}$ is taken up by the norepinephrine transporter (NET) and accumulates in sympathetic neurons. Thus, the kinetics of ${ }^{11} \mathrm{C}-\mathrm{HED}$ can be used to assess tissue NET activity and by inference, the density of sympathetic innervation. Accordingly, the objectives of this paper were to determine the utility of ${ }^{11} \mathrm{C}$-HED in assessing sympathetic innervation in human BAT and to test whether ${ }^{11} \mathrm{C}-\mathrm{HED}$ uptake at rest could predict the level of metabolic activation of BAT during cold stress. In addition, we assessed the contribution of subcutaneous and visceral WAT to cold-induced energy expenditure in lean young adults.

\section{MATERIALS AND METHODS}

\section{Subjects}

Twenty adult lean normal subjects (10 women and 10 men; mean age $\pm \mathrm{SD}, 23.3 \pm 3.8 \mathrm{y}$; body mass index, $23.7 \pm 2.5 \mathrm{~kg} / \mathrm{m}^{2}$ ) were 
studied. The study was approved by the Wayne State University Institutional Review Board, and written consent was obtained from all participants. All subjects underwent ${ }^{11} \mathrm{C}$-meta-hydroxyephedrin $\left({ }^{11} \mathrm{C}-\mathrm{HED}\right)$ and ${ }^{15} \mathrm{O}$-water PET imaging at rest and after exposure to mild cold $\left(16^{\circ} \mathrm{C}\right)$. In addition, ${ }^{18} \mathrm{~F}$-FDG images were obtained during the cold stress condition to assess the presence of activated BAT. Mild cold exposure was applied using a specialized whole-body garment, which incorporates a network of small-diameter plastic tubing (Allen Vangard, Inc.) (Supplemental Fig. 1; supplemental materials are available at http://jnm.snmjournals.org). Details with respect to the cooling procedure are provided in the supplemental materials. Subjects were closely monitored during the cold exposure period for signs of shivering. In addition to monitoring the skin temperature, subjects reported every $5 \mathrm{~min}$ about their subjective feeling of cold and if shivering was likely to occur, the water temperature in the garment was raised. Postexperimental debriefing verified that all subjects experienced the cold condition as a pain-free cold sensation without substantial discomfort.

\section{${ }^{11} \mathrm{C}$-HED Kinetic Model}

Previous mechanistic studies of the ${ }^{11} \mathrm{C}-\mathrm{HED}$ tracer have established high neuronal selectivity, long neuronal retention times, and a correlation between tissue retention of tracer and tissue norepinephrine concentration (14). On the basis of previous studies in animals (13) and humans (15), a comprehensive compartmental model of myocardial ${ }^{11} \mathrm{C}$-HED kinetics has been developed (Supplemental Fig. 2). Because the NET transport rate of ${ }^{11} \mathrm{C}$-HED $\left(k_{3}\right)$ is much faster than the rate of clearance back into plasma $\left(k_{3} \gg k_{2}\right)$, most of the ${ }^{11} \mathrm{C}$-HED molecules delivered from plasma to the extracellular space are rapidly transported into the neurons. This causes the neuronal uptake of ${ }^{11} \mathrm{C}$-HED to be rate-limited by delivery from plasma into interstitium $\left(K_{1}\right)$, rather than by NET transport $\left(k_{3}\right)$. Supporting this view, ${ }^{11} \mathrm{C}$ HED retention has been previously shown to be flow dependent in the dog heart (16). Moreover, because of a high lipophilicity $(\log P=0.31)$, the ${ }^{11} \mathrm{C}$-HED tracer continuously leaks from sympathetic nerve terminals during the PET study $\left(k_{4}\right)(16)$. Thus, ${ }^{11} \mathrm{C}$-HED tissue retention is a complex function of tracer delivery and washout, both strongly affected by blood flow. In fact, the situation is even more complicated because the relationship between ${ }^{11} \mathrm{C}$-HED retention and blood flow changes for different levels of norepinephrine release in the synaptic cleft due to competitive inhibition of ${ }^{11} \mathrm{C}$-HED uptake at the NET. Unfortunately, correcting for flow effects is not straightforward even if one has flow estimates available. To do so would require a detailed knowledge of the dependence of the tracer's retention on flow to perform a proper flow normalization of the ${ }^{11} \mathrm{C}-\mathrm{HED}$ retention values, information that is unavailable.

\section{PET Data Acquisition}

All subjects were scanned using a Discovery STE PET/CT (GE Healthcare) scanner in 3-dimensional mode, except for the ${ }^{15} \mathrm{O}$-water scans, which were performed in 2-dimensional mode to decrease contribution of scatter from outside the field of view (FOV). Initially, a venous catheter was established for tracer injection. One venous blood sample $\left(0.5 \mathrm{~cm}^{3}\right.$ total $)$ was collected to determine hematocrit levels; moreover, arterial oxygen saturation (pSat) was monitored during the whole protocol using a Dinamap ProCare 400 monitor (GE Healthcare). The protocol started with 2 low-level CT scans $(100 \mathrm{kVp}, 60 \mathrm{~mA})$ for attenuation correction, one at the location of the neck/shoulder region (also including the ascending aorta inferior to the aortic arch) and the other at the level of subcutaneous WAT in the lower abdomen (including the descending aorta). After acquisition of the transmission scans, ${ }^{15} \mathrm{O}$-water $(1.1 \mathrm{GBq})$ was injected as a slow bolus over $20 \mathrm{~s}$, and a 2-min dynamic PET scan of the neck/shoulder region was obtained $(60 \times 2 \mathrm{~s})$. After a 10 -min period to allow for decay of tracer (the half-life of ${ }^{15} \mathrm{O}$ is $2 \mathrm{~min}$ ), the ${ }^{15} \mathrm{O}$-water scan was repeated with the lower abdomen in the FOV. Subsequently the patient was repositioned with the neck/shoulder region in the FOV, and after a 10-min period to allow for tracer decay, ${ }^{11} \mathrm{C}-\mathrm{HED}$ (370 MBq) was injected as a slow bolus over $20 \mathrm{~s}$. Coinciding with the tracer injection, a dynamic scan was initiated $(12 \times 10,3 \times 60$, and $4 \times 300 \mathrm{~s})$. At the conclusion of the dynamic scan, the patient was repositioned with the lower abdomen in the FOV, and a static scan $(8 \mathrm{~min})$ of abdominal WAT was obtained. During the entire baseline protocol, subjects were kept in a thermoneutral condition by maintaining the suit water temperature at $31^{\circ} \mathrm{C}-34^{\circ} \mathrm{C}$. After the baseline protocol, subjects were exposed to mild cold temperature for the rest of the study by changing the circulating water temperature to $15^{\circ} \mathrm{C}-17^{\circ} \mathrm{C}$. After a cooling period of at least 1-h duration, the baseline protocol was repeated. At its conclusion, the ${ }^{18} \mathrm{~F}-\mathrm{FDG}$ tracer $(150 \mathrm{MBq})$ was injected, and after a 50 -min uptake period a 4-bed-position PET/CT scan was acquired, covering the torso from the shoulder to the lower abdomen. All PET emission data were corrected for attenuation, scatter, and random events and then iteratively reconstructed into $128 \times 128 \times 47$ matrices (voxel dimensions, $5.47 \times 5.47 \times 3.27 \mathrm{~mm}$ ) using the ordered-subset expectation maximization algorithm provided by the manufacturer ( 2 iterations, 20 subsets, and postprocessing gaussian filter with $6.0 \mathrm{~mm}$ in full width at half maximum). The final spatial resolution of the image volumes was approximately $7 \mathrm{~mm}$ in full width at half maximum.

\section{Image Data Processing and Analysis}

To calculate blood flow and tracer retention, the arterial input functions need to be known. The validity of an image-derived input function obtained from the ascending aorta (AA) for accurate quantification of myocardial perfusion has been shown in several ${ }^{15} \mathrm{O}$-water studies that compared flow values obtained using the image-derived input function with those determined using arterial blood sampling $(17,18)$. A 3-dimensional region of interest (ROI, 1-cm diameter) was defined over the AA using the AMIDE software, and spillover from the left atrium was avoided by considering only planes in which the left atrium was not visible. The resulting time-activity curve was subsequently corrected for partial-volume effects by taking into account the diameter of the AA obtained from CT $(2.3 \pm 0.3 \mathrm{~cm})$ and the full width at half maximum of the reconstructed PET images (19). To extrapolate the AA time-activity curve beyond the initial $25 \mathrm{~min}$, the curve was fitted with a triexponential function, and the slowest exponential was used for continuation of the input function up to $40 \mathrm{~min}$ after injection. An analogous approach was used for the abdominal scans using the descending aorta (DA). It was shown that this method is in good agreement with the arterial function, because the DA is relatively free of spillover from other organs and extends from the upper thorax to the lower abdomen (20). The ROIs representing supraclavicular BAT as well as subcutaneous and visceral WAT were defined in CT images based on the density of adipose tissue ( -250 to -50 Hounsfield units). ROIs representing subcutaneous WAT (WAT) were defined at the level of the lower abdomen superior to the hip joint, whereas visceral WAT (viscWAT) ROIs were defined below the kidneys. An ROI at the location of the deltoid muscle was assumed to be representative for muscle tissue. BAT was considered as activated if there were areas of tissue that were more than $5 \mathrm{~mm}$ in diameter and had a minimal SUV (defined as tracer concentration in $\mathrm{MBq} / \mathrm{cm}^{3}$ normalized to injected activity 
(MBq) per weight $(\mathrm{g})$ ) of ${ }^{18} \mathrm{~F}-\mathrm{FDG}$ of at least 2.0. BAT volume was determined by thresholding both the CT image volume $(-250<$ Hounsfield units $<-50$ ) and the ${ }^{18}$ F-FDG volume (SUV $>2.0$ ) and then applying the logical AND operation to the 2 masks, followed by removal of all areas that were smaller than $0.125 \mathrm{~cm}^{3}$. The volume of BAT ROIs $\left(\mathrm{cm}^{3}\right)$ was converted into weight $(\mathrm{g})$ by assuming a density of $0.90 \mathrm{~g} / \mathrm{cm}^{3}$. Regional time-activity curves were derived from ${ }^{15} \mathrm{O}$-water and ${ }^{11} \mathrm{C}$-HED scans and blood flow $\mathrm{F}(\mathrm{mL} /$ $\mathrm{g} / \mathrm{min}$ ), and ${ }^{11} \mathrm{C}$-HED retention index (RI) was estimated from the following equations

$P E T\left(t_{i}\right)=F \int_{0}^{\mathrm{t}_{\mathrm{i}}} C_{A A}(u) \times e^{-\frac{F}{\lambda}\left(t_{\mathrm{i}}-u\right)} d u \mathrm{RI}=C_{(30-40)}^{H E D} / \int_{0}^{40} C_{A A}(u) d u$,

Eq. 1

where $\operatorname{PET}\left(t_{i}\right)$ is the measured time-activity curve $\left(\mathrm{MBq} / \mathrm{cm}^{3}\right)$ obtained from the dynamic ${ }^{15} \mathrm{O}$-water injection, and $\lambda$ is the partition coefficient of tissue to blood $(0.92 \mathrm{~mL} / \mathrm{g})$. Finally, the RI in tissue was calculated as the quotient between the average ${ }^{11} \mathrm{C}$-HED tracer concentration in BAT or WAT tissues 30-40 min after injection and the integral of ${ }^{11} \mathrm{C}$-HED tracer concentration in blood (21). As mentioned earlier, because of the dynamic recycling of the ${ }^{11} \mathrm{C}$-HED tracer at the neuronal membrane, the ${ }^{11} \mathrm{C}$-HED RI is a complex function of both blood flow and norepinephrine concentration. Although an exact flow normalization of the ${ }^{11} \mathrm{C}$-HED RI is problematic, we applied an approximate blood flow correction of BAT ${ }^{11} \mathrm{C}$-HED uptake by dividing the RI (\%) by the independently measured perfusion values $(\mathrm{mL} / 100 \mathrm{~g} / \mathrm{min})$. This flow-corrected $\mathrm{RI}$ in BAT is denoted as $\mathrm{RI}_{\mathrm{fc}}$ and is presented in addition to the noncorrected RI. Because blood flow in subcutaneous WAT is similar at cold and during thermoneutral conditions $(22,23),{ }^{11} \mathrm{C}$-HED retention in WAT can be regarded as a reflection of the number or integrity of norepinephrine terminals (15) in WAT during these states. Finally, when the previously established oxygen extraction fractions (OEFs) for BAT (0.50), WAT (0.40), and muscle (0.30) (23) were used, the metabolic rate of oxygen $\left(\mathrm{MRO}_{2} ; \mathrm{mL} / 100 \mathrm{~g} / \mathrm{min}\right)$ in tissue was calculated as the product of blood flow (F; mL/100 g/min), OEF (unitless), and arterial oxygen concentration $\left(\mathrm{cO}_{2} ; \mathrm{mlO}_{2} / 100 \mathrm{~mL}\right)$ as follows:

$$
\begin{gathered}
\mathrm{MRO}_{2}\left(\frac{\mathrm{mL}}{\text { gmin }}\right)=\mathrm{F}\left(\frac{\mathrm{mL}}{\mathrm{gmin}}\right) \times \mathrm{OEF} \times \mathrm{cO}_{2}\left(\frac{\mathrm{mLO}_{2}}{100 \mathrm{~mL}}\right) \\
\mathrm{cO}_{2}\left(\frac{\mathrm{mLO}_{2}}{100 \mathrm{~mL}}\right)=\left(\frac{\mathrm{HCT}}{3}\right) \times(1.36 \mathrm{pSat})+\left(0.0031 \mathrm{pO}_{2}(\text { torr })\right),
\end{gathered}
$$

where $\mathrm{cO}_{2}$ is derived from the patient's arterial oxygen saturation (pSat; \%), the hematocrit (HCT), and the partial pressure of $\mathrm{O}_{2}$ $\left(\mathrm{pO}_{2}\right)$, which is calculated from the measured pSat according to Severinghaus' formula and the exact inversion by Ellis (24). Finally, the daily energy expenditure (DEE; $\mathrm{kcal} / \mathrm{d}$ ) was calculated from the obtained $\mathrm{MRO}_{2}$ and the weight of BAT according to the formula

$$
\begin{aligned}
\operatorname{DEE}\left(\frac{\mathrm{kcal}}{\text { day }}\right)= & \mathrm{MRO}_{2}\left(\frac{\mathrm{mL}}{\mathrm{gmin}}\right) \times \text { weight }(\mathrm{g}) \times 0.0048\left(\frac{\mathrm{kcal}}{\mathrm{mL}}\right) \\
& \times 1,440\left(\frac{\mathrm{min}}{\text { day }}\right),
\end{aligned}
$$

Eq. 4

where the conversion factor between $\mathrm{kcal}$ and $\mathrm{ml} \mathrm{O}_{2}$ was assumed for a respiratory quotient of 0.80 (25). Finally, we assume $1 \mathrm{~g}$ is approximately $1 \mathrm{~mL}$.

\section{Whole-Body Indirect Calorimetry}

Measurement of energy expenditure $(\mathrm{kcal} / \mathrm{d})$ under resting and cold conditions was performed using the VO2000 Portable Metabolic Testing System (MedGraphics). For both conditions, subjects were measured while lying in a relaxed position, in a fasted state for at least $6 \mathrm{~h}$. Subjects were fitted with neoprene face masks, and all measurements were taken using the low flow pneumotachs. Heart rate (beats/min), oxygen consumption $\left(\mathrm{VO}_{2}, 1 / \mathrm{min}\right)$, carbon dioxide pro-

\begin{tabular}{|c|c|c|c|c|}
\hline Parameter & All subjects & High BAT & Low BAT & $P$ \\
\hline Subjects & 20 (10 women/10 men) & 13 (8 women/5 men) & 7 (2 women/5 men) & \\
\hline Height (cm) & $172 \pm 12$ & $170 \pm 13$ & $175 \pm 12$ & NS \\
\hline Weight (kg) & $69 \pm 16$ & $65 \pm 16$ & $76 \pm 17$ & NS \\
\hline Body mass indext $\left(\mathrm{kg} / \mathrm{m}^{2}\right)$ & $23.0 \pm 2.6$ & $22.0 \pm 2.1$ & $24.8 \pm 2.4$ & 0.03 \\
\hline Body fat (\%) & $25.4 \pm 5.8$ & $25.3 \pm 6.3$ & $25.5 \pm 5.2$ & NS \\
\hline BAT mass (g) & $68 \pm 49$ & $96 \pm 37$ & $16 \pm 4$ & $<0.01$ \\
\hline WAT mass $(\mathrm{kg})$ & $17.4 \pm 4.9$ & $16.3 \pm 5.5$ & $19.5 \pm 3.6$ & NS \\
\hline Visceral fat area $\left(\mathrm{cm}^{2}\right)$ & $36.5 \pm 19.4$ & $32.3 \pm 19.6$ & $44.1 \pm 18.1$ & NS \\
\hline BAT SUV $\max$ & $16.2 \pm 8.8$ & $19.5 \pm 8.0$ & $7.2 \pm 1.7$ & $<0.01$ \\
\hline BAT metabolic activity (g) & $468 \pm 450$ & $609 \pm 451$ & $81 \pm 22$ & $<0.01$ \\
\hline BAT DEE, resting (kcal/d) & $1,469 \pm 401$ & $1,349 \pm 403$ & $1,712 \pm 337$ & NS \\
\hline$\Delta$ Whole-body DEE $(\mathrm{kcal} / \mathrm{d})$ & $223 \pm 396$ & $340 \pm 380$ & $9 \pm 361$ & NS \\
\hline$\Delta$ Whole-body DEE (\%) & $10.5 \pm 21.3$ & $17.1 \pm 16.5$ & $0.8 \pm 23.4$ & NS \\
\hline $\begin{array}{l}\mathrm{NS}=\text { not significant. } \\
\text { Data are mean } \pm \text { SD }(P \text { value }\end{array}$ & en groups). & & & \\
\hline
\end{tabular}
duction $\left(\mathrm{VCO}_{2}, \mathrm{l} / \mathrm{min}\right)$, and respiratory quotient $\left(\mathrm{VCO}_{2} / \mathrm{VO}_{2}\right)$ were all

TABLE 1

Descriptive Statistics of Subjects in High-BAT and Low-BAT Groups 


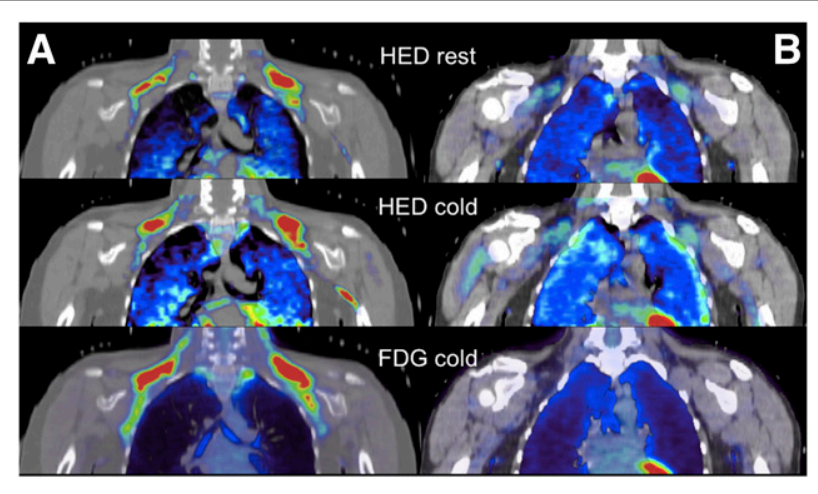

FIGURE 1. ${ }^{11} \mathrm{C}$-HED PET tracer uptake in supraclavicular BAT during thermoneutral condition (HED rest, upper row), during cold exposure (HED cold, middle row), and ${ }^{18} \mathrm{~F}-\mathrm{FDG}$ tracer uptake during cold exposure (FDG cold, bottom row) in subject with cold-activated BAT (A) and subject without cold-activated BAT (B).

measured for $10 \mathrm{~min}$. Whole-body DEE was then calculated on the basis of the Weir equation (26) using the BreezeSuite software (version 6.0; MedGraphics).

\section{Statistical Analysis}

Data are reported as mean $\pm \mathrm{SD}$, and all analysis was performed with SPSS software (version 21; IBM Corp.). ${ }^{18} \mathrm{~F}$-FDG uptake in BAT after cold exposure was highly variable, with a few subjects (all women) showing extensive uptake in the cervical-supraclavicular depots. A histogram of cold-activated BAT mass showed 2 distinct peaks with maxima at $10-20 \mathrm{~g}$ and at $80-90 \mathrm{~g}$ (Supplemental Fig. 3). To account for the bimodal distribution, subjects were divided into 2 groups (high BAT and low BAT), with the threshold separating the 2 groups set to $20 \mathrm{~g}$ of activated BAT. Normally distributed continuous variables were compared between the 2 groups using an independent-sample $t$ test and nonnormally distributed continuous variables using the Mann-Whitney $U$ test. Finally, correlations between variables were assessed using Pearson $r$. All reported $P$ values are 2-tailed, and values less than 0.05 were considered to indicate statistical significance.

\section{RESULTS}

\section{Descriptive Statistics}

Table 1 shows descriptive statistics characterizing the subject population. The study population consisted of lean (body mass index, $23.0 \pm 2.6 \mathrm{~kg} / \mathrm{m}^{2}$ ) young (age, $25.1 \pm 5.2 \mathrm{y}$ ) controls (10 men and 10 women) without any indication for cardiovascular or diabetic disease. We observed a wide variation in cold-activated BAT ranging from 0 to $182 \mathrm{~g}$, characterized by a bimodal distribution. After cold exposure, about two-thirds of the subjects showed relatively high BAT activation ( $\sim 100 \mathrm{~g}$, high-BAT group), whereas one-third of the subjects displayed low BAT activation ( $<20 \mathrm{~g}$, low-BAT group). The $\mathrm{SUV}_{\max }$ determined in the highBAT group was significantly higher than that measured in the lowBAT group $(19.5 \pm 8.0$ vs. $7.2 \pm 1.7 ; P<0.01)$. Moreover, the prevalence of a significant amount of activated BAT was higher in women (8/10) than men (5/10) — the average activated BAT mass was determined as $88 \pm 55 \mathrm{~g}$ in women whereas it was $50 \pm 38 \mathrm{~g}$ in men $(P=0.12)$. Conforming to the measured body mass index values, the visceral fat area was found to be higher in the low-BAT group, despite the virtually identical body fat percentage.

As expected from previous work $(4,5,27)$, the 2 groups showed different responses in their DEE to mild cold exposure. In the high-BAT group, the baseline DEE was lower than in the low-BAT group; however, during mild cold exposure the DEE increased by about $17 \%$ (from $1,349 \pm 309$ to $1,689 \pm 463 \mathrm{kcal} / \mathrm{d}, P=0.015$ ). In contrast, cold exposure failed to increase energy expenditure in the low-BAT group (change, 1,712 \pm 337 to $1,722 \pm 312 \mathrm{kcal} / \mathrm{d}$, Table 1). Moreover, whereas absolute changes in DEE were always positive in the high-BAT group (range, 48-783; mean, $340 \pm 380 \mathrm{kcal} / \mathrm{d})$, DEE changes in the low-BAT group varied considerably (range, -496-538; mean, $9 \pm 361 \mathrm{kcal} / \mathrm{d}$ ).

Finally, the respiratory quotient $\left(\mathrm{VCO}_{2} / \mathrm{VO}_{2}\right)$ was marginally lower in the high-BAT than in the low-BAT group $(0.85 \pm 0.06$ vs. $0.91+0.11 ; P=0.16)$, suggesting greater levels of resting fat oxidation in this group (28). However, respiratory quotient values were not significantly affected by cold stress.

\section{${ }^{11} \mathrm{C}$-HED Uptake in Supraclavicular BAT}

We determined a significant increase in ${ }^{11} \mathrm{C}-\mathrm{HED}$ RI in the supraclavicular BAT of high-BAT subjects both in the absence and in the presence of cold stress. Moreover, ${ }^{11} \mathrm{C}$-HED RI corresponded to cold-activated ${ }^{18}$ F-FDG tracer uptake (Fig. 1). More specifically, we observed a highly significant correlation between the RI under resting conditions $\left(\mathrm{RI}_{\text {rest }}\right)$ and the amount of BAT mass $\left(R^{2}=0.68\right.$, $P<0.01$ ), indicating that ${ }^{11} \mathrm{C}-\mathrm{HED}$ uptake during thermoneutral condition is a good predictor of cold-activated BAT mass. RI under cold conditions $\left(\mathrm{RI}_{\mathrm{cold}}\right)$ was also highly correlated with ${ }^{18} \mathrm{~F}-\mathrm{FDG}$ uptake $\left(R^{2}=0.73, P<0.01\right)$ (Fig. $\left.2 \mathrm{~A}\right)$. Moreover, as predicted based on the characteristics of the ${ }^{11} \mathrm{C}$-HED tracer, we found that blood flow and $\mathrm{RI}_{\text {rest }}\left(R^{2}=0.48, P=\right.$ $0.04)$ as well as $\mathrm{RI}_{\text {cold }}\left(R^{2}=0.72, P<0.01\right.$, Fig. 2B) were highly correlated. In addition, a significant correlation was found between the $\mathrm{RI}_{\text {rest }}$ and $\mathrm{RI}_{\text {cold }}\left(R^{2}=0.62, P<0.01\right)$. Taken together, our results indicate that the abundance of NETs, and by inference the level of sympathetic innervation, in BAT predicts the magnitude of cold-induced activation in this tissue.

\section{${ }^{11} \mathrm{C}-$ HED Uptake in Subcutaneous WAT}

In contrast to the significant increase of ${ }^{11} \mathrm{C}$-HED RI in supraclavicular BAT after
FIGURE 2. Linear relationship between supraclavicular BAT mass and $\mathrm{Rl}$ at both rest and cold (A) and between BAT mass and blood flow in BAT (B). Graphs indicate linear relationships between RIs and BAT mass at both conditions and between BAT mass and blood flow. 


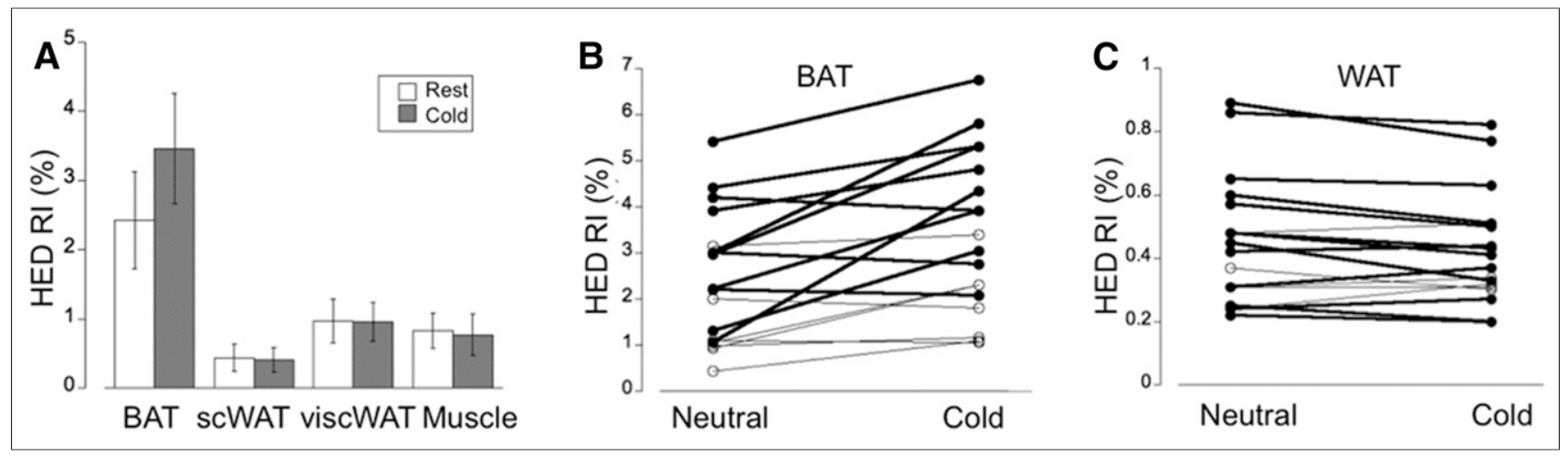

FIGURE 3. (A) ${ }^{11} \mathrm{C}-\mathrm{HED}$ PET tracer uptake quantified using the RI, defined as tracer concentration in tissue at 30-40 min after injection divided by integral of blood input function from 0 to $40 \mathrm{~min}$. Graph demonstrates overall significant increase in RI at location of supraclavicular BAT (BAT), but not at subcutaneous WAT (WAT) and visceral WAT (viscWAT). (B) Variable increase in Rl after cold exposure determined at location of supraclavicular BAT (BAT). (C) In contrast, RI in subcutaneous WAT (WAT) shows consistent decrease after cold exposure.

cold exposure, ${ }^{11} \mathrm{C}$-HED RI in both subcutaneous and visceral WAT as well as muscle was similar during cold and neutral conditions (Fig. 3A). Interestingly, ${ }^{11} \mathrm{C}-\mathrm{HED}$ RI in visceral WAT was found to be about twice that in subcutaneous WAT (Table 2). In addition, whereas the increase in ${ }^{11} \mathrm{C}$-HED RI at the location of supraclavicular BAT after cold exposure was increased during cold (Fig. 3B), we determined a consistent decrease (albeit small) in ${ }^{11} \mathrm{C}-\mathrm{HED} \mathrm{RI}$ after cold exposure at the location of subcutaneous WAT (Fig. 3C). These data suggest that even in subjects with a significant amount of cold-activated supraclavicular BAT, the contribution of WAT to overall energy expenditure is modest at best. The decrease in ${ }^{11} \mathrm{C}-\mathrm{HED}$ RI observed in both subcutaneous WAT and visceral WAT is most likely a consequence of lower blood flow in these tissues during cold exposure.

\section{Relationship Between Blood Flow and Sympathetic Innervation}

To assess the relationship among blood flow, sympathetic innervation, and glucose uptake in supraclavicular BAT and subcutaneous WAT, ${ }^{15} \mathrm{O}$-water-derived flow values, ${ }^{11} \mathrm{C}$-HED-derived RI, and ${ }^{18}$ F-FDG SUV measures were compared. Figure 4 illustrates this relationship, indicating a tight association among these 3 physiologic

TABLE 2

HED RI in supraclavicular BAT, subcutaneous WAT, and visceral WAT at Thermoneutral and Cold Condition Observed in High-BAT and Low-BAT Groups

\begin{tabular}{ccccc}
\hline Parameter & All subjects & High BAT & Low BAT & $P$ \\
\hline RI rest (BAT) & $2.42 \pm 0.85$ & $3.05 \pm 1.0$ & $1.42 \pm 0.6$ & $<0.01$ \\
\hline RI cold (BAT) & $3.43 \pm 0.93^{*}$ & $4.27 \pm 1.1^{*}$ & $1.91 \pm 0.6$ & $<0.01$ \\
\hline $\mathrm{RI}$ rest (WAT) & $0.44 \pm 0.22$ & $0.46 \pm 0.19$ & $0.42 \pm 0.23$ & $\mathrm{NS}$ \\
\hline $\mathrm{RI}$ cold (WAT) & $0.41 \pm 0.18$ & $0.44 \pm 0.18$ & $0.38 \pm 0.19$ & $\mathrm{NS}$ \\
\hline $\begin{array}{c}\mathrm{R} \text { rest } \\
\text { (viscWAT) }\end{array}$ & $0.97 \pm 0.32$ & $1.03 \pm 0.33$ & $0.87 \pm 0.40$ & $<0.01$ \\
$\begin{array}{c}\text { RI cold } \\
\text { (viscWAT) }\end{array}$ & $0.96 \pm 0.28$ & $1.00 \pm 0.29$ & $0.86 \pm 0.34$ & $<0.01$ \\
\hline
\end{tabular}

${ }^{\star} P<0.05$ between rest and cold.

$\mathrm{NS}=$ not significant; visc $=$ visceral.

Data are mean \pm SD ( $P$ value between groups). parameters. Moreover, we determined a highly significant correlation between cold-activated BAT mass and the $\mathrm{RI}_{\mathrm{fc}}$ under thermoneutral conditions $\left(R^{2}=0.54, P<0.01\right.$, Fig. 5) but not during cold stress $\left(R^{2}=0.13, P>0.05\right)$. More important, analysis of blood flow and uncorrected ${ }^{11} \mathrm{C}$-HED RI at rest by multiple regression indicates that both blood flow and ${ }^{11} \mathrm{C}-\mathrm{HED} \mathrm{RI}_{\text {rest }}$ were significant independent predictors of BAT mass (partial regression of 0.50 for blood flow and 0.17 for $\operatorname{HED}[P=0.012])$.

\section{Energy Expenditure in BAT and WAT}

On the basis of our previous work that established values for the $\mathrm{OEF}$ at thermoneutral and cold conditions (22) and the measured blood flow values, we calculated DEE in supraclavicular BAT and subcutaneous WAT (Fig. 6). An OEF value of 0.50 was used for supraclavicular BAT, whereas an OEF value of 0.40 was used for subcutaneous WAT (22). Our current results confirm our previous findings, indicating a low contribution of supraclavicular BAT to DEE of less than $20 \mathrm{kcal} / \mathrm{d}$, even for subjects with a relatively large amount of activated BAT (96 $\pm 37 \mathrm{~g}$ in the high-BAT group). Our findings indicate a DEE of approximately $7 \mathrm{kcal} / \mathrm{d}$ (range, $1.6-12 \mathrm{kcal} / \mathrm{d}$ ) at thermoneutral conditions, which increases to between 10 and $20 \mathrm{kcal} / \mathrm{d}$ (range, 4.7-29 kcal/d) after cold exposure (Fig. 6A). Specifically, in the high-BAT group we determined a significantly increased DEE in BAT after cold exposure $(7.5 \pm$ 5.3 vs. $10.9 \pm 7.6 \mathrm{kcal} / \mathrm{d}, P<0.01)$, whereas in the low-BAT group the DEE at the location of BAT was much lower and similar during thermoneutral and cold conditions $(0.70 \pm 0.66$ vs. $0.91 \pm$ $0.64 \mathrm{kcal} / \mathrm{d})$. Although the blood flow and metabolic rate was found to be much lower in subcutaneous WAT, because of the large mass $(17.4 \pm 4.9 \mathrm{~kg}$, Table 1$)$ the associated DEE was found to be considerable $(\sim 150 \mathrm{kcal} / \mathrm{d})$. Interestingly, although DEE in WAT was found to be similar at thermoneutral condition in the high-BAT and low-BAT groups (150 \pm 72 vs. $148 \pm 39 \mathrm{kcal} / \mathrm{d})$, it was substantially decreased in both groups during cold exposure, most likely due to decreased perfusion. In the high-BAT group, the decrease was approximately $25 \%$ (to $115 \pm 55 \mathrm{kcal} / \mathrm{d}$ ) whereas in the low-BAT group the decrease was approximately $40 \%$ (to $89 \pm$ $40 \mathrm{kcal} / \mathrm{d}, P<0.01$, Fig. 6B).

\section{DISCUSSION}

The aim of this study was to quantify sympathetic innervation in both supraclavicular BAT and subcutaneous WAT in lean young 


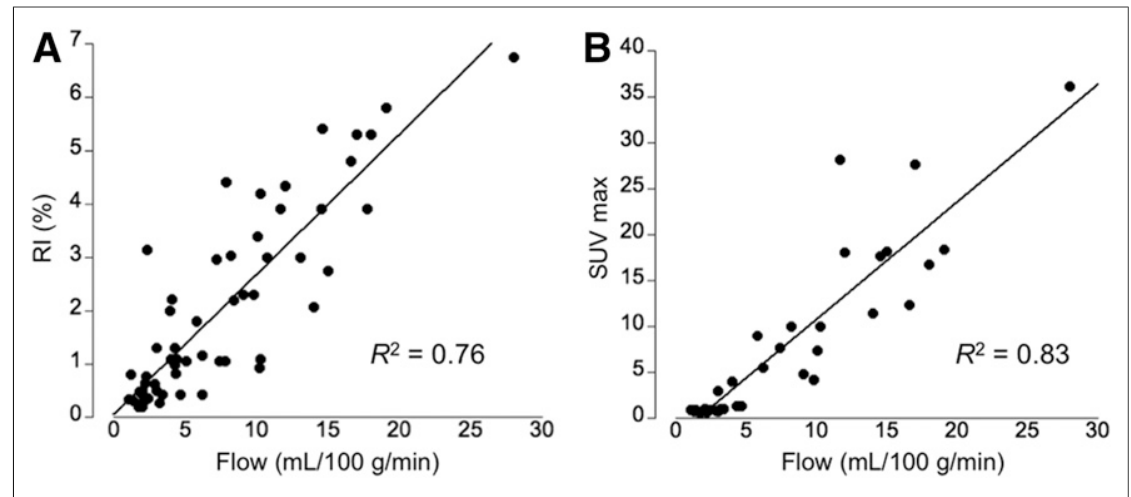

FIGURE 4. (A) Linear relationship between blood flow (mL/100 $\mathrm{g} / \mathrm{min})$ and sympathetic innervation as measured using $\mathrm{Rl}$ at location of supraclavicular BAT and subcutaneous WAT during both rest and cold exposure. (B) Linear relationship between blood flow and SUV $\mathrm{max}_{\text {ax }}$ at location of supraclavicular BAT and subcutaneous WAT during cold exposure.

adults during both thermoneutral and cold exposure conditions as well as to relate sympathetic innervation in these tissues to blood flow and glucose uptake. The data presented here indicate that the presence of cold-activated BAT can be predicted by ${ }^{11} \mathrm{C}-\mathrm{HED}$ tracer uptake during thermoneutral conditions.

There are several key outcomes from this work: first, we determined a linear relationship between blood flow $(\mathrm{mL} / 100 \mathrm{~g} / \mathrm{min})$ and sympathetic innervation (RI\%) in both BAT and WAT as measured by ${ }^{11} \mathrm{C}-\mathrm{HED}$ PET imaging, reflecting the well-established coupling of blood flow with sympathetic innervation (29). Second, whereas sympathetic innervation (and associated blood flow) increased after cold exposure in supraclavicular BAT, both these measures slightly decreased in subcutaneous WAT, resulting in a decreased contribution of WAT to whole-body DEE during the cold state. The observed cold-induced vasoconstriction in WAT suggests decreased heat production, as it is unlikely that an increase in thermogenic capacity of subcutaneous WAT would not be accompanied by a simultaneous increase in perfusion to supply fuel and oxygen as well as to dissipate the generated heat throughout the body. Thus, our findings point to a situation in which WAT appears to play an

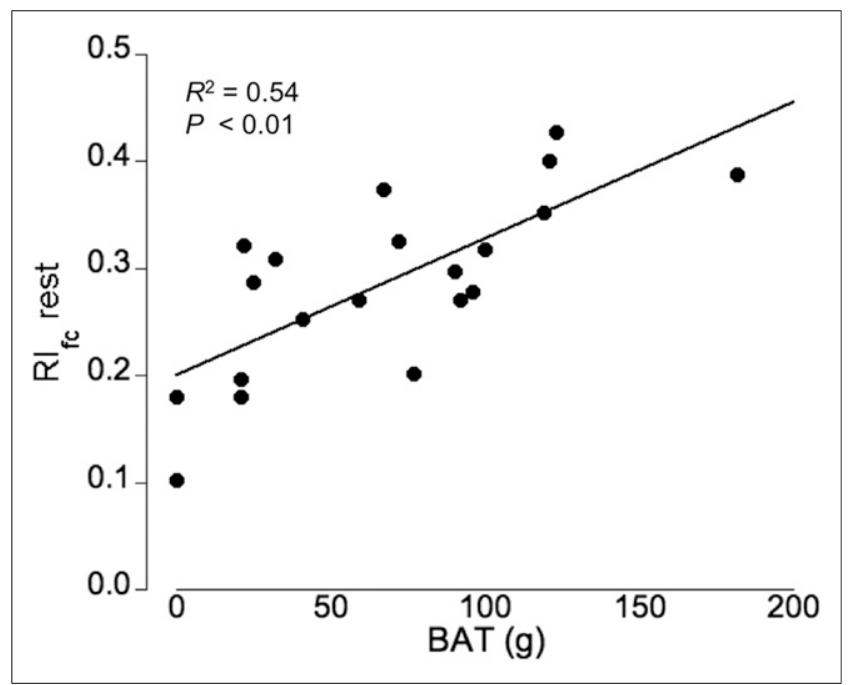

FIGURE 5. Significant relationship between flow-corrected $\mathrm{RI}\left(\mathrm{RI}_{\mathrm{fc}}\right)$ at thermoneutral condition (rest) and cold-activated BAT mass $(P<0.01)$. insulative role rather than a metabolic one in combatting cold stress, with a physiologic response that targets reduction of heat loss rather than generation of heat. Interestingly, the decrease in WAT DEE during cold exposure was found to be somewhat lower in the high-BAT group than in the low-BAT group; however, the relevance of this finding is presently unclear.

\section{WAT Oxidative Metabolism}

Our findings indicate that the resting oxygen metabolic rate $\left(\mathrm{MRO}_{2}\right)$ of subcutaneous WAT is $0.13 \pm 0.04 \mathrm{~mL} / 100 \mathrm{~g} / \mathrm{min}$ at rest and decreases to $0.09+0.03 \mathrm{~mL} / 100 \mathrm{~g} / \mathrm{min}$ during mild cold. These values result in a specific metabolic rate in subcutaneous WAT of approximately $7.5 \mathrm{kcal} / \mathrm{kg} / \mathrm{d}$, which is close to the previously estimated metabolic rate of approximately $5 \mathrm{kcal} / \mathrm{kg} / \mathrm{d}$ based on a mechanistic model $(30,31)$. Moreover, our $\mathrm{MRO}_{2}$ values for subcutaneous WAT compare well with those in muscle, which have been reported as about $0.2 \mathrm{~mL} / 100 \mathrm{~g} / \mathrm{min}$ (equivalent to $\sim 12 \mathrm{kcal} / \mathrm{kg} / \mathrm{d}$ ), reflecting the expected rank order of $\mathrm{MRO}_{2}$ in tissues. In contrast, the observed $\mathrm{MRO}_{2}$ values for visceral WAT in the range of $0.25-$ $0.30 \mathrm{~mL} / 100 \mathrm{~g} / \mathrm{min}$ (equivalent to $15-18 \mathrm{kcal} / \mathrm{kg} / \mathrm{d}$ ) appear to be high, especially in comparison with muscle $\mathrm{MRO}_{2}$. Although an increased metabolic rate in visceral WAT cannot be completely excluded, the measurement of PET activity at the location of visceral WAT is problematic because of the small sampled volumes that are subject to spillover from adjacent organs. This situation is in stark contrast to the sampling of subcutaneous WAT depots, which are much larger and therefore allow definition of timeactivity curves that are free of partial-volume effects.

\section{WAT and Whole-Body Energy Expenditure}

It is now well established that cold stress increases the oxidative metabolism in human BAT depots (32). We and others (33) have observed that cold-induced increases in whole-body energy expenditure (average of $\sim 220 \mathrm{kcal} / \mathrm{d}$ in the present study) are strongly correlated with the presence of cold-activated BAT depots. Furthermore, activation of human BAT depots appears to be selectively induced by cold stress, but not by nonselective sympathomimetic activation (4). Nonetheless, these PET-defined BAT depots account for less than $5 \%$ of the total cold-induced increase in metabolism, an observation supported by other recent reports $(34,35)$. Moreover, these investigators have also presented data that suggest that deep, centrally located muscles of the neck, back, and inner thigh are the greatest contributors to cold-induced thermogenesis via activation of muscle shivering on a microscale level, with BAT possibly assuming a more endocrine role.

Because of decreased blood flow in subcutaneous WAT during cold exposure, it is unlikely that WAT directly contributes to coldinduced whole-body energy expenditure. Nevertheless, our data suggest a higher thermogenic capacity of WAT in subjects with large amount of activated BAT (high-BAT group) than in subjects with a low amount of BAT (low-BAT group), indicating a common physiologic network mediating the effect of nonshivering thermogenesis in both tissues. The decrease in the contribution of WAT to DEE was found to be about twice as large in the low-BAT group than in the high-BAT group ( $\sim 60 \mathrm{vs} . \sim 30 \mathrm{kcal} / \mathrm{d})$, leaving open the interpretation that this difference in WAT DEE involves activation 


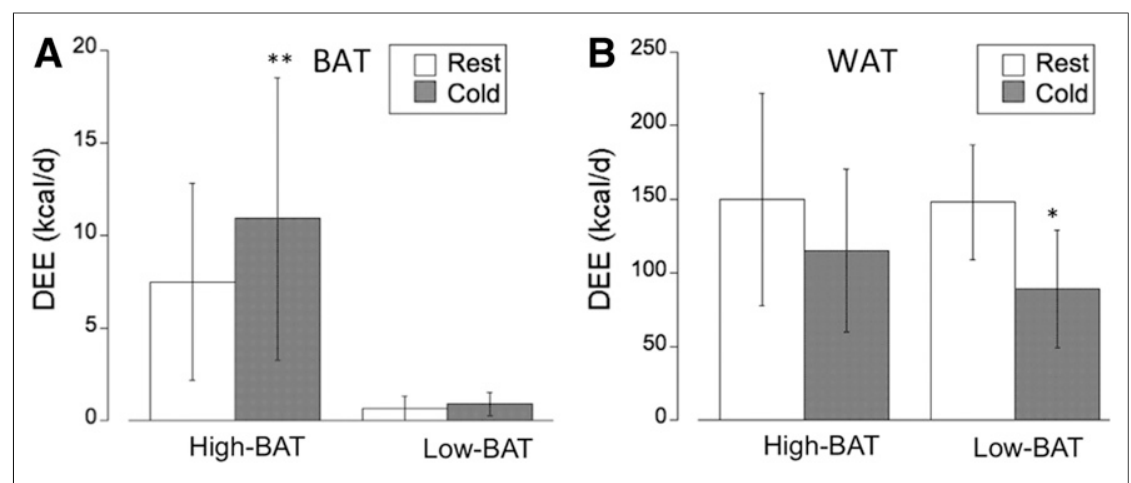

FIGURE 6. (A) Contribution of supraclavicular BAT (BAT) determined in our subject group to DEE at thermoneutral (rest) and cold conditions. Graph indicates small contribution of BAT to whole-body DEE in range of $<20 \mathrm{kcal} / \mathrm{d}$. (B) In contrast, contribution of subcutaneous WAT (WAT) to whole-body DEE is much higher because of large WAT mass, although cold exposure results in substantial decrease in WAT DEE. ${ }^{*} P<0.01 .{ }^{\star} P<0.05$.

of beige adipocytes that can be recruited by cold stress or adrenergic agonists, but that are too diffuse to be imaged by PET.

\section{Relationship Between Blood Flow and ${ }^{18}$ F-FDG Uptake}

The accumulation of ${ }^{18} \mathrm{~F}-\mathrm{FDG}$ in tissues is generally believed to represent the rate of glycolytic metabolism. Delivery of the tracer to the tissue is obviously essential, and blood flow may play an important role in the ultimate ${ }^{18} \mathrm{~F}-\mathrm{FDG}$ tissue uptake observed. The relationship between blood flow and ${ }^{18}$ F-FDG tissue uptake has been extensively studied in human tumors using PET imaging $(36,37)$. These studies have clearly demonstrated a strong relationship between blood flow and SUV or metabolic rate of glucose, with correlation coefficients in the range of $0.7-0.8(36,38)$. The blood flow range in these studies was almost identical to that observed in our BAT studies (5-30 mL/100 g/min). Conceptually, the strong relationship between blood flow and ${ }^{18} \mathrm{~F}-\mathrm{FDG}$ tissue uptake is a consequence of the fact that the unidirectional inflow parameter for ${ }^{18} \mathrm{~F}-\mathrm{FDG}\left(K_{1}\right)$ is highly correlated with blood flow $(r=0.84)$, whereas the fraction of ${ }^{18} \mathrm{~F}-\mathrm{FDG}$ in cytosol being metabolized $\left(k_{3} /\left[k_{2}+k_{3}\right]\right)$ is not related to blood flow $(r<0.1)$ (36). Thus, given the fact that the K-complex is the product of $K_{1}$ and the fraction of metabolizeable glucose inside the cell $\left(=k_{3} /\right.$ $\left[k_{2}+k_{3}\right]$ ), the obtained glucose metabolic rate (and SUV) are directly related to blood flow. Further support for the strong correlation between ${ }^{18} \mathrm{~F}$-FDG tissue uptake and blood flow stems from studies that compare cerebral perfusion based on arterial spinlabeling MRI with ${ }^{18}$ F-FDG PET uptake $(39,40)$. These authors concluded that ${ }^{18} \mathrm{~F}$-FDG PET and arterial spin-labeling MRI identify similar regional abnormalities and have comparable diagnostic accuracy. Thus, the observed high SUVs in BAT might reflect primarily increased blood flow with a relatively low increase in metabolic activity, reflected by the accompanying low oxygen consumption of BAT tissue (22).

Along the same lines, given the observed significant increase in BAT perfusion during cold $(\sim 7 \mathrm{~mL} / 100 \mathrm{~g} / \mathrm{min}$ equal to $\sim 10 \mathrm{~L} / 100$ $\mathrm{g} / \mathrm{d})$ and the fact that the temperature of blood is equal to the core body temperature $\left(37^{\circ} \mathrm{C}\right.$ or $\left.98.6^{\circ} \mathrm{F}\right)$, a significant amount of additional heat is transported from the core to BAT during cold exposure. The amount of additional heat energy (kcal) reaching BAT during cold exposure can be calculated using the heat capacity of blood $\left(3.49 \mathrm{~kJ} / \mathrm{kg} /{ }^{\circ} \mathrm{C}\right)$ and assuming a conservative core $/$ surface temperature gradient of about $3{ }^{\circ} \mathrm{C}(41)$, yielding a value of approximately $25 \mathrm{kcal} / \mathrm{d}$ for a BAT mass of $100 \mathrm{~g}$. Thus, the heat supplied to BAT by blood flow from the core likely exceeds the heat generated in BAT by a factor of 3 . These observations suggest that an important function of BAT innervation might be the redistribution of core heat to critical regions in the supraclavicular and spinal regions. In this regard, norepinephrine infusion was recently shown to dramatically increase blood flow to murine BAT in the absence of UCP1mediated thermogenesis (42).

\section{Comparison with Other Work}

Because tissue $\mathrm{MRO}_{2}$ (and the associated energy expenditure) is the product of blood flow and oxygen extraction, blood flow sets the upper limit of tissue oxygen consumption. In this regard, we note that the cold-induced increase in supraclavicular BAT blood flow reported in this study is nearly identical to that reported by other investigators (27). Thus, on the basis of available blood flow data one can deduce that acutely activated human BAT contributes very little to cold-induced energy expenditure, even if one assumes $100 \%$ OEF. These values are consistent with recent tracer experiments showing that the energy content of glucose (27) or nonesterified fatty acids (32) taken up by active BAT is trivial when compared with cold-induced energy expenditure (33). Finally, the energy content of cold-induced glucose uptake in human BAT was reported by various investigators $(6,27,34)$ to amount to less than $10 \mathrm{kcal} / \mathrm{d}$ if fully oxidized, in agreement with our findings.

The existence of cold-induced thermogenesis that is independent of BAT is well documented, particularly in warm-adapted animals $(43,44)$. These sites of thermogenesis remain poorly defined but could involve elevated metabolism in muscle (45). The defense against cold is likely an innate property of mammals, and browning of subcutaneous WAT was originally one more layer of defense against the cold, in addition to other mechanisms that mediate nonshivering thermogenesis, such as futile cycling of the $\mathrm{Ca}^{2+}$-ATPase (SERCA) pump in muscle (46). Our data suggest that during human evolution the importance of WAT browning for protection against acute cold diminished, but still might play a role in seasonal adaptation to cold. Despite the paucity of studies investigating seasonal changes in whole-body energy expenditure, there are reports of higher metabolic rates during the winter than summer (47-49). Thus, even though seasonal changes of WAT thermogenesis were not the focus of our study, such changes are of particular interest, because they indicate a physiologic response to colder weather even in a modern society, where indoor temperature is regulated and without the provocative stimulated cooling that is usually required to stimulate BAT.

\section{CONCLUSION}

The main result of our study is that the contribution of subcutaneous WAT to whole-body energy expenditure during acute cold exposure is negative. The cold-induced decrease in WAT energy expenditure is less pronounced in subjects with a high amount of activated supraclavicular BAT, leaving open the possibility that in these subjects beige adipocytes exist that can be activated by long-term (seasonal) exposure to cold. Finally, our 
data indicate that differences in the level of sympathetic innervation are, at least partially, responsible for the widely observed variability of cold-activated BAT mass in lean subjects.

\section{DISCLOSURE}

This study was supported by a grant from NIDDK (R01DK10245501). No other potential conflict of interest relevant to this article was reported.

\section{REFERENCES}

1. Cinti S. Between brown and white: novel aspects of adipocyte differentiation. Ann Med. 2011;43:104-115.

2. Sharp LZ, Shinoda K, Ohno H, et al. Human BAT possesses molecular signatures that resemble beige/brite cells. PLoS One. 2012;7:e49452.

3. Dempersmier J, Sambeat A, Gulyaeva O, et al. Cold-inducible Zfp516 activates UCP1 transcription to promote browning of white fat and development of brown fat. Mol Cell. 2015;57:235-246.

4. Cypess AM, Chen YC, Sze C, et al. Cold but not sympathomimetics activates human brown adipose tissue in vivo. Proc Natl Acad Sci USA. 2012;109:10001-10005.

5. Cypess AM, Lehman S, Williams G, et al. Identification and importance of brown adipose tissue in adult humans. $N$ Engl J Med. 2009;360:1509-1517.

6. Virtanen KA, Lidell ME, Orava J, et al. Functional brown adipose tissue in healthy adults. $N$ Engl J Med. 2009;360:1518-1525.

7. Sidossis L, Kajimura S. Brown and beige fat in humans: thermogenic adipocytes that control energy and glucose homeostasis. J Clin Invest. 2015;125:478-486.

8. Murano I, Barbatelli G, Giordano A, Cinti S. Noradrenergic parenchymal nerve fiber branching after cold acclimatisation correlates with brown adipocyte density in mouse adipose organ. J Anat. 2009;214:171-178.

9. Morrison SF, Ramamurthy S, Young JB. Reduced rearing temperature augments responses in sympathetic outflow to brown adipose tissue. J Neurosci. 2000;20:9264 9271.

10. Contreras GA, Lee YH, Mottillo EP, Granneman JG. Inducible brown adipocytes in subcutaneous inguinal white fat: the role of continuous sympathetic stimulation. Am J Physiol Endocrinol Metab. 2014;307:E793-E799.

11. Raffel DM, Chen W, Sherman PS, Gildersleeve DL, Jung YW. Dependence of cardiac ${ }^{11} \mathrm{C}$-meta-hydroxyephedrine retention on norepinephrine transporter density. J Nucl Med. 2006;47:1490-1496.

12. Fricke E, Fricke H, Eckert S, et al. Myocardial sympathetic innervation in patients with chronic coronary artery disease: is reduction in coronary flow reserve correlated with sympathetic denervation? Eur J Nucl Med Mol Imaging. 2007;34:206-211.

13. Thackeray JT, Beanlands RS, Dasilva JN. Presence of specific ${ }^{11} \mathrm{C}$-meta-hydroxyephedrine retention in heart, lung, pancreas, and brown adipose tissue. $\mathrm{J} \mathrm{Nucl}$ Med. 2007;48:1733-1740.

14. Rosenspire KC, Haka MS, Van Dort ME, et al. Synthesis and preliminary evaluation of carbon-11-meta-hydroxyephedrine: a false transmitter agent for heart neuronal imaging. J Nucl Med. 1990;31:1328-1334.

15. Raffel DM, Wieland DM. Assessment of cardiac sympathetic nerve integrity with positron emission tomography. Nucl Med Biol. 2001;28:541-559.

16. DeGrado TR, Hutchins GD, Toorongian SA, Wieland DM, Schwaiger M. Myocardial kinetics of carbon-11-meta-hydroxyephedrine: retention mechanisms and effects of norepinephrine. J Nucl Med. 1993;34:1287-1293.

17. Lubberink M, Harms HJ, Halbmeijer R, de Haan S, Knaapen P, Lammertsma AA. Low-dose quantitative myocardial blood flow imaging using ${ }^{15} \mathrm{O}$-water and PET without attenuation correction. $J$ Nucl Med. 2010;51:575-580.

18. van der Veldt AA, Hendrikse NH, Harms HJ, et al. Quantitative parametric perfusion images using ${ }^{15} \mathrm{O}$-labeled water and a clinical PET/CT scanner: testretest variability in lung cancer. $J$ Nucl Med. 2010;51:1684-1690.

19. Germano G, Chen BC, Huang SC, Gambhir SS, Hoffman EJ, Phelps ME. Use of the abdominal aorta for arterial input function determination in hepatic and renal PET studies. J Nucl Med. 1992;33:613-620.

20. Ohtake T, Kosaka N, Watanabe T, et al. Noninvasive method to obtain input function for measuring tissue glucose utilization of thoracic and abdominal organs. J Nucl Med. 1991;32:1432-1438.

21. Allman KC, Wieland DM, Muzik O, Degrado TR, Wolfe ER Jr, Schwaiger M. Carbon-11 hydroxyephedrine with positron emission tomography for serial assessment of cardiac adrenergic neuronal function after acute myocardial infarction in humans. J Am Coll Cardiol. 1993;22:368-375.

22. Muzik O, Mangner TJ, Granneman JG. Assessment of oxidative metabolism in brown fat using PET imaging. Front Endocrinol (Lausanne). 2012;3:15.
23. Muzik O, Mangner TJ, Leonard WR, Kumar A, Janisse J, Granneman JG. ${ }^{15} \mathrm{O}$ PET measurement of blood flow and oxygen consumption in cold-activated human brown fat. $J$ Nucl Med. 2013;54:523-531.

24. Ellis RK. Determination of PO2 from saturation. J Appl Physiol. 1989;67:902-906.

25. Leonard WR. Measuring human energy expenditure and metabolic function: basic principles and methods. J Anthropol Sci. 2010;88:221-230.

26. Weir JB. New methods for calculating metabolic rate with special reference to protein metabolism. J Physiol (Lond). 1949;109:1-9.

27. Orava J, Nuutila P, Lidell ME, et al. Different metabolic responses of human brown adipose tissue to activation by cold and insulin. Cell Metab. 2011;14:272-279.

28. McArdle WD, Katch FI, Katch VL. Exercise Physiology: Energy, Nutrition, and Human Performance. 5th ed. Philadelphia, PA: Lippincott, Williams \& Wilkins; 2001.

29. Guyenet PG. The sympathetic control of blood pressure. Nat Rev Neurosci. 2006; 7:335-346.

30. Wang Z, Ying Z, Bosy-Westphal A, et al. Evaluation of specific metabolic rates of major organs and tissues: comparison between men and women. Am J Hum Biol. 2011;23:333-338.

31. Elia M. Organ and tissue contribution to metabolic rate. In: Kinney JM, Tucker HN, eds. Energy Metabolism: Tissue Determinants and Cellular Corollaries. New York, NY: Raven Press; 1992:61-80.

32. Ouellet V, Labbé SM, Blondin DP, et al. Brown adipose tissue oxidative metabolism contributes to energy expenditure during acute cold exposure in humans. $J$ Clin Invest. 2012;122:545-552.

33. Yoneshiro T, Aita S, Matsushita M, et al. Brown adipose tissue, whole-body energy expenditure, and thermogenesis in healthy adult men. Obesity (Silver Spring). 2011;19:13-16.

34. Din M, Raiko J, Saari T, et al. Human brown adipose tissue $\left[{ }^{15} \mathrm{O}\right] \mathrm{O} 2 \mathrm{PET}$ imaging in the presence and absence of cold stimulus. Eur J Nucl Med Mol Imaging. 2016;43:1878-1886.

35. Blondin DP, Labbé SM, Phoenix S, et al. Contributions of white and brown adipose tissues and skeletal muscles to acute cold-induced metabolic responses in healthy men. J Physiol (Lond). 2015;593:701-714.

36. Zasadny KR, Tatsumi M, Wahl RL. FDG metabolism and uptake versus blood flow in women with untreated primary breast cancers. Eur J Nucl Med Mol Imaging. 2003;30:274-280.

37. Mullani NA, Herbst RS, O'Neil RG, Gould KL, Barron BJ, Abbruzzese JL. Tumor blood flow measured by PET dynamic imaging of first-pass ${ }^{18}$ F-FDG uptake: a comparison with ${ }^{15}$ O-labeled water-measured blood flow. J Nucl Med. 2008;49:517-523.

38. Mankoff DA, Dunnwald LK, Gralow JR, et al. Blood flow and metabolism in locally advanced breast cancer: relationship to response to therapy. $J$ Nucl Med. 2002;43:500-509.

39. Verfaillie SC, Adriaanse SM, Binnewijzend MA, et al. Cerebral perfusion and glucose metabolism in Alzheimer's disease and frontotemporal dementia: two sides of the same coin? Eur Radiol. 2015;25:3050-3059.

40. Musiek ES, Chen Y, Korczykowski M, et al. Direct comparison of fluorodeoxyglucose positron emission tomography and arterial spin labeling magnetic resonance imaging in Alzheimer's disease. Alzheimers Dement. 2012;8:51-59.

41. Olesen BW. Thermal comfort. Aldebaran website. http://aldebaran.feld.cvut.cz/ vyuka/environmental_engineering/lectures/L10\%20Thermal\%20Comfort.pdf. 1982. Accessed March 14, 2017.

42. Abreu-Vieira G, Hagberg CE, Spalding KL, Cannon B, Nedergaard J. Adrenergically stimulated blood flow in brown adipose tissue is not dependent on thermogenesis. Am J Physiol Endocrinol Metab. 2015;308:E822-E829.

43. Foster DO, Frydman ML. Nonshivering thermogenesis in the rat. II. Measurements of blood flow with microspheres point to brown adipose tissue as the dominant site of the calorigenesis induced by noradrenaline. Can J Physiol Pharmacol. 1978;56:110-122.

44. Ukropec J, Anunciado RP, Ravussin Y, Hulver MW, Kozak LP. UCP1-independent thermogenesis in white adipose tissue of cold-acclimated Ucp1-/- mice. $J$ Biol Chem. 2006;281:31894-31908.

45. Wijers SL, Schrauwen P, van Baak MA, Saris WH, van Marken Lichtenbelt WD. Beta-adrenergic receptor blockade does not inhibit cold-induced thermogenesis in humans: possible involvement of brown adipose tissue. J Clin Endocrinol Metab. 2011;96:E598-E605.

46. Bal NC, Maurya SK, Sopariwala DH, et al. Sarcolipin is a newly identified regulator of muscle-based thermogenesis in mammals. Nat Med. 2012;18:1575-1579.

47. Kashiwazaki H, Dejima Y, Suzuki T. Influence of upper and lower thermoneutral room temperatures (20 degrees $\mathrm{C}$ and 25 degrees $\mathrm{C}$ ) on fasting and post-prandial resting metabolism under different outdoor temperatures. Eur J Clin Nutr. 1990;44:405-413.

48. Plasqui G, Kester ADM, Westerterp KM. Seasonal variation in sleeping metabolic rate, thyroid activity, and leptin. Am J Physiol Endocrinol Metab. 2003;285:E338-E343.

49. Leonard WR, Levy SB, Tarskaia TA, et al. Seasonal variation in basal metabolic rates among the Yakut (Sakha) of northeastern Siberia. Am J Hum Biol. 2014;26:437-445. 